\title{
Effects of diversity and coalescence of species assemblages on ecosystem function at the margins of an environmental shift
}

\author{
Jo A. Werba ${ }^{\text {Corresp., } 1}$, Alexandra L. Stucy ${ }^{2}$, Ariane L. Peralta ${ }^{2}$, Michael W. McCoy ${ }^{2}$ \\ 1 Department of Biology, McMaster University, Hamilton, Ontario, Canada \\ 2 Department of Biology, East Carolina University, Greenville, North Carolina, United States \\ Corresponding Author: Jo A. Werba \\ Email address: jo.werba@gmail.com
}

Sea level rise is mixing formerly isolated freshwater communities with saltwater communities. The structure of these new aquatic communities is jointly controlled by preand post-colonization processes. Similarly, since salinity is a strong abiotic determinant of post-colonization survival in coastal systems, changes in salinity will likely impact community composition. In this study, we examine how a strong abiotic gradient affects the diversity and structure of bacterial and zooplankton communities and associated ecosystem functions (decomposition and carbon mineralization). We ran a six week dispersal experiment using mesocosm ponds with four distinct salinity profiles $(0,5,9$, and $13 \mathrm{psu}$ ). We find that salinity is the primary driver of both bacterial and zooplankton community composition. We find evidence that as bacterial richness increases so does the amount of decomposition. A phenomenological model suggests carbon mineralization may decrease at mid-salinities; this warrants future work into possible mechanisms for this apparent loss of function. Understanding how salinization changes community structure and ecosystem function may be paramount for managing and conserving coastal plain ecosystems where salinity is increasing due to sea level rise, saltwater intrusion, storm surges, and drought. 


\title{
Effects of diversity and coalescence of
} species assemblages on ecosystem function at the margins of an environmental shift

\author{
Jo A. Werba ${ }^{1}$, Alexandra L. Stucy ${ }^{2}$, Ariane L. Peralta ${ }^{2}$, and Michael W. \\ McCoy $^{2}$ \\ ${ }^{1}$ Department of Biology, McMaster University, 1280 Main Street West, Hamilton, ON, \\ Canada, L8S 4K1 \\ ${ }^{2}$ Department of Biology, East Carolina University, Greenville, NC 27858
}

Corresponding author:

Jo A. Werba ${ }^{1}$

Email address: jo.werba@gmail.com

\begin{abstract}
Sea level rise is mixing formerly isolated freshwater communities with saltwater communities. The structure of these new aquatic communities is jointly controlled by pre- and post-colonization processes. Similarly, since salinity is a strong abiotic determinant of post-colonization survival in coastal systems, changes in salinity will likely impact community composition. In this study, we examine how a strong abiotic gradient affects the diversity and structure of bacterial and zooplankton communities and associated ecosystem functions (decomposition and carbon mineralization). We ran a six week dispersal experiment using mesocosm ponds with four distinct salinity profiles $(0,5,9$, and $13 \mathrm{psu})$. We find that salinity is the primary driver of both bacterial and zooplankton community composition. We find evidence that as bacterial richness increases so does the amount of decomposition. A phenomenological model suggests carbon mineralization may decrease at mid-salinities; this warrants future work into possible mechanisms for this apparent loss of function. Understanding how salinization changes community structure and ecosystem function may be paramount for managing and conserving coastal plain ecosystems where salinity is increasing due to sea level rise, saltwater intrusion, storm surges, and drought.

Keywords: dispersal, ecosystem function, decomposition, carbon mineralization, abiotic filter, salinization, climate change
\end{abstract}

\section{INTRODUCTION}

Salinity is an abiotic filter for almost all aquatic organisms, and therefore strongly influences their distribution and abundance. Changes in salinity can alter the distribution of organisms (Hall and Burns, 2002), community assembly processes (Jones and McMahon, 2009), and associated ecosystem functions (Schäfer et al., 2012; Wieski et al., 2010). Thus, understanding how communities are altered following changes in habitat quality is critical for predicting the consequences of environmental change.

Changes in salinity due to climate change associated sea level rise (SLR), coastal storm surges, ditching and dredging, over-extraction of aquifers, and increased input of salts from upstream sources greatly affect coastal wetlands (Nicholls and Cazenave, 2010; Craft et al., 2009). Specifically, SLR and ocean over-wash from storm surges change the chemical make up of coastal freshwater bodies and increase the movement of organisms between salt and freshwater habitat types, creating new species assemblages by merging communities that were historically allopatric. Furthermore, increases in salinity, alkalinity, $\mathrm{pH}$, and ion concentrations from salt water incursions into freshwater habitats is toxic to many freshwater organisms (e.g. Albecker and McCoy, 2017; Hintz and Relyea, 2017), creating a physiological barrier that affects the composition of freshwater communities. Changes in abiotic conditions, disturbance regime, and dispersal dynamics in coastal ponds are therefore likely affect both the composition of species 
and the ecological functions of the system, which can ultimately jeopardize important socio-economic services provided by these ecosystems (de Groot et al., 2002; Kirwan and Megonigal, 2013). For instance, zooplankton abundance and diversity is known to be negatively correlated with salinity (Nielsen et al., 2008; Helenius et al., 2017; Schallenberg et al., 2003), and decreased diversity is often associated with reductions in grazing rates (Zervoudaki et al., 2009), nutrient cycling (Makarewicz and Likens, 1979) and other downstream functions such as carbon export (Isla et al., 2015). Indeed, both zooplankaton and microbes are widely recognized for their essential role in biogeochemical processes that control flows of carbon, nitrogen and phosphorus (Hébert et al., 2016b) in wetland systems (Schimel and Schaeffer, 2012; Herbert et al., 2015). Since salinity is recognized as a primary determinate of both zooplankton (Bate et al., 2002; Kimmel, 2011; Breckenridge et al., 2015) and bacterial communities, salinization of wetlands might be expected to have particularly strong affects on wetland systems.

Despite the likely widespread dispersal of most microorganisms, a large review of fresh and marine species found little overlap between habitats, confirming that salinity acts as a large abiotic barrier for most microorganisms (Logares et al., 2009). Microbial functional groups also change along a salinity gradient (Dupont et al., 2014; Eiler et al., 2014; Coci et al., 2005; Langenheder et al., 2003) which suggests that increases in salinity in freshwater ponds could shift the abundance, richness and functional processes of bacterial communities that are critical in all ecosystems. However, the potential effects of changes in salinity on important downstream ecosystem functions, such as litter decomposition and carbon mineralization, are not well understood.

Rates of decomposition may differ as a function of salinity, the type of litter, micro- and macro-fauna present in the community, and the time since decomposition began. For instance, the home field advantage hypothesis (Hunt et al., 1988; Gholz et al., 2000) suggests that decomposition rate is most efficient when leaf litter is being decomposed in its natural habitat. That is, terrestrial species (e.g. Acer sp.) will decompose best in freshwater, while marine species (e.g Fucus sp.) will decompose fastest in marine systems. However, evidence for this hypothesis is quite mixed (Franzitta et al., 2015; Lettice et al., 2011; Quintino et al., 2009; Reice and Herbst, 1982; Lopes et al., 2011; Connolly et al., 2014) and decomposition may be determined better by nitrogen and lignin content rather than salinity (Stagg et al., 2018).

Carbon mineralization also differs across wetland habitat type. Estuarine wetlands rapidly sequester carbon, accounting for approximately 30\% of carbon sequestration in the lower USA (Bridgham et al., 2006), and they retain this stored carbon for longer than other ecosystems (Mcleod et al., 2011). Although precisely calculating the carbon budgets of wetlands is complicated by their concomitant release of methane gas, they are nevertheless generally considered to serve as an important net carbon sink in the long term (Mitsch et al., 2013). Unfortunately, coastal and estuarine wetlands are vulnerable to biogeochemical changes due to SLR and other environmental perturbations and are rapidly being lost (Hopkinson et al., 2012). In addition, higher salinity soils often have lower levels of carbon mineralization and methane gas release (Setia et al., 2011; Weston et al., 2006; Al-Busaidi et al., 2014; Poffenbarger et al., 2011), although these results are not universal (Chambers et al., 2011). Regardless, understanding how carbon budgets may change as wetlands change is critical for understanding and mitigating impacts of climate change.

Our study examines the impacts of salinization on species diversity, community structure and associated ecosystem functions in coastal shallow freshwater wetlands. We examined how overwash events along with mixing of freshwater and saltwater taxa affect the diversity and composition of bacteria and zooplankton communities and downstream ecosystem functions. To test the effects of salinization on diversity and ecosystem function we performed a semi-natural mesocosm experiment in which we simulated wetlands with different salinities. We simulated the effects of salt-water incursions and the mixing of salt and freshwater communities by imposing two treatments: one that included a sample of both fresh and 13 psu plankton and microbes, and a second that was a sample of salt-only plankton and microbe communities. We quantified changes in zooplankton and bacteria communities and measured two representative ecosystem functions: carbon mineralization and litter decomposition. We expected that differences in species identities and diversity among patches would translate into differences in aggregate ecosystem functions (Staddon et al., 2010; Symons and Arnott, 2013; Dodson, 1992). To gain more clarity on how decomposition changes across salinities we tested the home field advantage hypothesis by measuring the decomposition of three species with different natural habitats over 6 weeks along a salinity gradient. Additionally, we hypothesize that differences in decomposition will be correlated with the associated microbial and zooplankton communities. Finally, to further enhance our understanding of how 
SLR and seawater overwash might affect the carbon cycle in the face of ongoing impacts from climate change, we examine how the zooplankton and bacterial communities correlate with carbon mineralization across the salinity gradient.

\section{METHODS}

\section{Experimental Set-Up}

Our experiment took place in North Carolina, USA. North Carolina is a suitable place for studying the effects of salinity because SLR is occurring faster there than in other regions on the US Atlantic coast (Kemp et al., 2009; Kopp et al., 2015).

We created 39 experimental ponds using $567 \mathrm{~L}$ stock watering tanks. Tanks were filled with $378 \mathrm{~L}$ of water from a hose; we recognize that by not sterilizing the water it is possible that bacteria were introduced in such a way that bacterial richness was disproportionately increased in freshwater communities. Instant Ocean sea salt was used to generate salinity treatments that closely matched the salinity of local coastal ponds $(0,5,9$ and $13 \mathrm{psu})$ (Albecker and McCoy, 2019). Tanks were randomly assigned to receive one of the four salinity treatments $(0,5,9$ and $13 \mathrm{psu})$, and each tank was initially seeded with zooplankton and bacteria from a natural pond with matching salinity (e.g. at 5 psu treatment was seeded with a community from a natural pond at $5 \mathrm{psu}$ ) located along the inner and outer banks of North Carolina on May 3, 2015 (supplementary Table S1). (N.B. samples from two different ponds were mixed for the highest salinity treatment).

We maintained "source" experimental ponds at 0 and 13 psu that were used to provide the colonists for the other experimental ponds. These species mixing treatments consisted of a "salt-only" plankton community which only received water from the 13 psu source tanks or "mixed" plankton treatment which received an aliquot of water and plankton consisting of equal volumes (each $50 \%$ of the total aliquot) sampled from the zero and 13 psu source tanks (Figure 1). Species mixing treatments were applied every nine days for a total of five species introductions over the course of the experiment. Plankton communities in all experimental ponds were sampled prior to each new introduction event. We chose this mixing regime to mimic the effects of saltwater over-wash and intrusion on freshwater wetlands since salinization events may be common in coastal ponds (Albecker and McCoy, 2019) and likely represent the unidirectional movement of saltwater species into freshwater communities. Each treatment combination was replicated four times, except for the $5 \mathrm{psu} /$ mixed mixing treatment which only had three replicates due to a leak in one experimental mesocosm.

To collect our initial zooplankton and bacteria from coastal ponds, we sampled along a single $100 \mathrm{~m}$ transect at each pond taking twenty $1 \mathrm{~L}$ samples of water from within a foot of the surface (most ponds were less than 2 feet deep at the time of sampling). We strained each sample them through a $62.5 \mu \mathrm{m}$ mesh filter. If a pond was too small to complete a full 100 meter transect, a second transect was used. These samples served as the starting communities for the experiment. In addition to samples from coastal ponds, the experimental tanks were seeded with peat moss to provide a nutrient pulse and the tank bottoms were covered with sand as a benthic substrate. Mesocosms were covered with $60 \%$ shade cloth to prevent macroinvertebrates and other higher trophic level organisms from colonizing.

Species mixing consisted of a $2 \mathrm{~L}$ aliquot of water from the source tanks; due to natural dynamics in these tanks the actual abundances varied for each mixing event (Table 1). On June 1, 2015, prior to beginning the experiment, we detected very low zooplankton abundance from the first seeding in the 13 psu tanks, so we re-seeded with a new wild sample of zooplankton. To allow populations to stabilize, the experiment began 6 weeks after initial seeding. For 45 days, we sampled all experimental ponds every 9 days. We had a 9 day sampling regime because this is long enough for most zooplankton species to complete at least one-generation cycle (Thompson and Shurin, 2012). Prior to sampling, we mixed each tank by stirring them in a circular motion around the perimeter five times. Twenty liters (approximately 5\% of total volume) of water was sampled from the water column at 20 random locations using an integrated tube sampler. After mixing we sampled from the center of the water column; we don't expect our tanks to be stratified due to their depth $(<0.6 \mathrm{~m})$ (Snucins and John, 2000). Samples were condensed through a $62.5 \mu \mathrm{m}$ filter into $25 \mathrm{~mL}$ containers. Zooplankton from each tank at the time of sampling were preserved in $10 \%$ formalin.

Zooplankton were counted in three $5 \mathrm{~mL}$ subsamples and identified to the lowest taxonomic level possible (order, family, or genus when feasible using Johnson and Allen (2012) and Pennak (1953)); however, for all analyses either family or order were used. Based on some known functional redundancy 
within zooplankton orders and family level taxonomic groupings (e.g. Barnett et al., 2007) we expected this level of resolution to be sufficient to capture major impacts of changes in assemblages on ecosystem functions.

\subsection{Bacterial sampling}

Bacterial sampling was concurrent to zooplankton sampling. At each sampling event we collected $1 \mathrm{~L}$ of water from each tank by scooping a bottle several times in the tank until we had $1 \mathrm{~L}$. Each $1 \mathrm{~L}$ bottle of water was homogenized and $200 \mathrm{~mL}$ of the water sample was concentrated onto $0.22 \mu \mathrm{m}$ filters within 24 hours of field sampling (Supor-200; Pall Gelman, East Hills, NY). Filters were transferred into $2 \mathrm{~mL}$ sterile tubes and stored at $-80^{\circ} \mathrm{C}$ until molecular analyses was completed.

\subsubsection{Bacterial Community Sequencing}

To examine shifts in bacterial community composition and diversity, bacteria in each mesocosm were characterized using paired-end targeted Illumina sequencing of the 16S rRNA gene (bacteria, archaea) (Caporaso et al., 2011). We extracted DNA from filters collected at 3 of the 6 time points representing the initial, middle, and final sampling days (Days 0, 18, 45). We extracted and purified the DNA from 0.22 $\mu \mathrm{m}$ supor filters from each mesocosm using the PowerWater DNA Isolation Kit (MO BIO Laboratories, Inc CA). We used this DNA as a template in PCR reactions. To characterize particle and free-living organism communities, we used barcoded primers (515FB/806RB) originally developed by the Earth Microbiome Project (Caporaso et al., 2012) to target the V4-V5 region of the bacterial 16S subunit of the ribosomal RNA gene (Apprill et al., 2015; Parada et al., 2016). This primer set targets Bacteria and Archaea. For this study, we focused on the bacteria. PCR products were combined in equimolar concentrations and sequenced using paired-end ( 2 × $250 \mathrm{bp}$ ) approach using the Illumina MiSeq platform at the Indiana University Center for Genomics and Bioinformatics.

Raw sequences were processed using the Mothur pipeline (version 1.39.4 Kozich et al., 2013; Schloss et al., 2009). Contigs from the paired end reads were assembled and quality trimmed using an average quality score, sequences were aligned to the Silva Database (version 123) (Quast et al., 2012), and chimeric sequences were removed using the VSEARCH algorithm (Rognes et al., 2016). Next, we created operational taxonomic units (OTUs) by splitting sequences based on taxonomic class and then clustering these OTUs by $97 \%$ sequence similarity. To estimate observed bacterial richness, we rarefied abundances to the minimum sequence depth of 13,000 reads. The original sequence data set had 12 million total sequences with 95,000 sequences per sample on average. After initial filtering there were 8.1 million sequences with 58,000 sequences on average per sample.

\subsection{Statistical Analyses} 0.2 .1 Alpha Diversity

We used richness to explore alpha diversity. Zooplankton taxonomic order richness was evaluated using a generalized linear model with a quasi-Poisson error distribution; a quasi-Poisson distribution was used because data were under-dispersed. For all Poisson distributed models, we evaluated under/over dispersion of our error distribution by looking at the ratio of Pearson's residuals and the residual degrees of freedom (Bolker, 2008). We defined observed bacterial richness by the number of different OTUs in a community. Over-dispersed observed bacterial richness was modeled using a negative binomial error distribution. Analyses were conducted using the lme 4 (Bates et al., 2015) and MASS (Venables and Ripley, 2013) packages, respectively, in the $\mathrm{R}$ statistical programming environment (R Core Team, 2016). Richness was modeled as a function of salinity, mixing treatment, time, and interactions between time and salinity and salinity and mixing. We included a random effect of replicate over time which allows the intercept and slope of each replicate to vary; this takes into account the grouping of repeated measures within each tank. For analysis, parameter-specific p-values in a fully parameterized model were used to determine the significance of predictors. We include results for Shannon Diversity in the supplement section 9.3.3.

\subsubsection{Testing for effects on community composition}

Community structure of both bacterial and zooplankton communities, including visualizing community turnover over time and turnover between treatments, was evaluated using Principle Coordinates Analysis (PCoA) with Bray-Curtis dissimilarity. The PCoA graphs (Figures 2,3) are generated based on a single ordination. Variation explained by mixing, salinity, and time was analyzed using a permutational multivariate analysis of variance (PERMANOVA). These analyses were conducted in R using the Vegan 
2.3. 3 package (Oksanen et al., 2016). We used indicator species analysis to identify which bacterial taxa were most representative of each salinity treatment (Dufrêne and Legendre, 1997). We used the Labdsv package in $\mathrm{R}$ to run the analysis (Roberts, 2016). For the indicator species analysis, we only included bacterial taxa with a relative abundance greater than 0.05 when summed across all tanks.

\subsection{Ecosystem Function}

We assessed the effects of salinity, zooplankton, bacteria, and species mixing on ecosystem functions using two different proxies for ecosystem function: decomposition amount and carbon mineralization of the final communities.

\subsubsection{Decomposition}

Leaf litter from three plant species were used in each tank to represent different habitat types: Spartina alterniflora found in salt marshes, Acer rubrum found in freshwater wetlands, and Phragmites australis found in both fresh and saltwater wetlands. We wanted to represent the three natural habitats along our gradient to understand the potential for differential effects of mixing on ecosystems along this salinity gradient. Leaves were harvested and air-dried in late May, 2015. Each tank received standardized amounts of leaf litter (Acer rubrum: $4.00 \mathrm{~g}$; stdev \pm 0.01 ; Spartina alterniflora: $6.99 \mathrm{~g}$ stdev \pm 0.03 ; Phragmites australis: $10.01 \mathrm{~g}$ stdev \pm 0.03 ). Phragmites australis and Acer rubrum were housed in 24 inch mesh mariculture bags, while Spartina alterniflora was housed in windowscreen bags with smaller holes since Spartina alterniflora was not securely retained within the mesh mariculture bags. Leaf litter remained in the tanks for the duration of the experiment. On day 45 , the bags were removed, air-dried, oven dried for 48 hours, and then weighed. Decomposition was quantified as the proportion of leaf dry weight loss (housed in decomposition bags) from the beginning to end of the experiment.

To determine the relationship between proportional change in dry weight and the predictor variables: observed bacterial richness, zooplankton richness, salinity, mixing treatment, leaf litter type, and the interaction of salinity and leaf litter type, we used a beta regression bet areg (Grün et al., 2012) (because the response is continuous and bounded between 0 to 1 ). We included the interaction between salinity and leaf litter type because we expected leaf litter would decompose differently in its native vs non-native abiotic conditions (e.g. Acer rubrum in freshwater verses the 13 psu water).

\subsubsection{Carbon Mineralization}

On the final sampling day (day 45), we measured the amount of $\mathrm{CO}_{2}$ respired from the aquatic communities using a laboratory-based bottle assay. Wheaton bottles $(125 \mathrm{~mL})$ fitted with septa were filled with water samples $(25 \mathrm{~mL})$ from each mesocosm tank. The $\mathrm{CO}_{2}$ concentration readings were determined using an LI-7000 Infrared Gas Analyzer (IRGA). On the day of collection (the final day of the experiment), bottles were filled with $25 \mathrm{~mL}$ of mesocosm tank water, and the gas samples were collected and analyzed immediately using the IRGA to determine the baseline $\mathrm{CO}_{2}$ concentration. A syringe was inserted into the septa and the headspace gas was mixed 3 times before pulling a sample and beginning analysis using the IRGA. This process was repeated on days 1,3 , and 7 following collection in order to determine $\mathrm{CO}_{2}$ respiration rates over time. To determine the $\mathrm{CO}_{2}$ production of each aquatic sample, the initial reading was subtracted from the analyzed day's reading. We made a calibration curve with a known concentration of $\mathrm{CO}_{2}$ over a set of known volumes to get the calibration curve. Then, the unknown gas samples from our sample set was compared to the known sample. To calculate the $\mathrm{CO}_{2}$ respiration rate, the concentration of $\mathrm{CO}_{2}$ calculated from the calibration curve was converted to volume units (ppm) using the following equation:

$$
C m\left(C O_{2}^{-C} L_{\text {headspace }}^{-1}\right)=\frac{C v \cdot M \cdot P}{R \cdot T}
$$

where $\mathrm{Cm}$ is carbon mineralization, $\mathrm{Cv}$ is the volume (ppm) of $\mathrm{CO}_{2}, \mathrm{M}$ is the molecular weight of carbon, $\mathrm{P}$ is $1 \mathrm{~atm}, \mathrm{R}$ is the universal gas constant $(0.0820575 \mathrm{~L}$ atm $\mathrm{K}$ mole), and $\mathrm{T}$ is the incubation temperature in Kelvin. This value is then multiplied by the volume of the incubation chamber $(\mathrm{L})$ and divided by the weight of water in the bottle used in the incubation to get $\mu \mathrm{g} \mathrm{CO}_{2}-\mathrm{C}$ gram ${ }^{-1}$ water. To get the rate, this number is divided by the number of days incubated to get $\mu \mathrm{g} \mathrm{CO}_{2}-\mathrm{C}$ gram water ${ }^{-1}$ day $^{-1}$.

We ran a linear model for carbon mineralization with zooplankton richness, microbial richness, mixing treatments, and salinity as predictors. In order to meet the assumptions of normality we log transformed 
the carbon mineralization data. There was a single replicate of a 9 psu tank that received the salt-only mixing treatment that was removed from the carbon mineralization analysis due to a missing data point.

After seeing the data we ran an a posteriori exploratory analysis where we used the same model as above but included a squared (quadratic) term for salinity to examine evidence of an intermediate minimum. We used AIC to compare models with and without the quadratic term.

\section{RESULTS}

\subsection{Alpha Diversity \\ 0.4.1 Zooplankton Community}

Differences in zooplankton family richness was not well described by any of the predictors used in our analyses (all $p>0.05$, Figure 4); for model parameter estimates see supplementary Table S2. We find similar results using Shannon Diversity (see Supplement section 9.3.3) For source tank richness see supplementary Figure S1.

\subsubsection{Bacterial Community}

Observed species richness for the bacterial community increased as salinity increased (estimate (log scale) $=0.035$, standard error $(\log$ scale $)=0.008, z=4.0, p=4.97 e-05)$, and over time (estimate $(\log$ scale $)=$ 0.008 , standard error $(\log$ scale $)=0.002, z=4.07, p=4.51 e-05)$ (Figure 5). However, the observed increase in richness over salinity reversed by the end of the experiment (Salinity:time: estimate (log scale $)=-0.001$, standard error $(\log$ scale $)=0.0003, z=-4.2, p=2.33 e-05)($ Figure 5 panel 3$)$. There were no clear differences as a result of the mixing treatments nor the interaction between salinity and mixing treatment ( $p>0.05$, see Supplementary Table S2 for coefficients). For source tanks richness see supplementary Figure S2. We find similar results when using Shannon Diversity (see Supplement section 9.3.3).

\subsection{Community Composition 0.5.1 Zooplankton Community}

Zooplankton communities initially aggregated into two distinct groups: a freshwater group and a group consisting of all other salinities (Figure 2). However, by the final day, the low salinity (5 psu) ponds receiving the mixed species treatment were more similar in composition to the freshwater community. The 9 and 13 psu salinity treatments remained distinct from freshwater treatments with regards to their community structure. PCoA one explained $31 \%$ of variation and PCoA two explained $14 \%$. PERMANOVA results suggest that salinity contributed most to variation in zooplankton communities $\left(R^{2}=0.23, p<0.0001\right)$. In contrast, the effects of the mixing treatment $\left(R^{2}=0.03, p<0.0001\right)$, time $\left(R^{2}=0.029, p<0.0001\right)$, and the interaction between time and salinity $\left(R^{2}=0.019, p<0.0001\right)$ on community variance were relatively more modest. While we observe an effect of the two and three way interactions between salinity, mixing, and time (all $p<0.05$, except the interaction of dispersal and salinity $p>0.05)$, the total amount of variation explained is quite small $\left(R^{2}<0.01\right.$ in all cases). For source tanks alone and source tanks in relation to all other tanks see Supplement Figures S3 and S4.

\subsubsection{Bacterial Community}

A mantel test revealed that zooplankton and bacterial communities were positively correlated (mantel test: $r=0.409, p=0.001$ ). For the bacterial community the main effects of salinity and time account for the most variation (PERMANOVA, salinity: $R^{2}=0.115, p=0.001$, time: $R^{2}=0.052, p<0.001$ ). Different mixing treatments did not have a clear differential effect on bacterial community structure (PERMANOVA, mixing: $R^{2}=0.007, p=0.786$ ). The bacterial communities in the treatment tanks separated into salt vs. freshwater environments along the primary axis, which explained $17.3 \%$ of the variation among communities (Figure 3). Distinct bacterial communities grouped according to increasing salinity $(5,9,13 \mathrm{psu})$ and separated along the secondary axis, which explained $7.3 \%$ of the variation in bacterial community composition. For information on the source tanks see the supplement Figures S5 and S6.

Indicator species analysis identified 225 bacterial taxa (OTUs) that were representative of salinity treatment (Supplementary Table S3). Associating these organisms with a salinity level can identify key taxa contributing to shifts in bacterial community structure. Due to the great diversity of bacterial communities, many bacterial sequences were unresolved to the 'species' level (operationally defined at 
97\% sequence similarity) but instead were classified according to the closest known sequence match Proteobacteria (phylum) was the strongest indicator of zero salinity (IndVal $=0.991)$. Rhodospirillales (class) was the second highest indicator taxon (IndVal $=0.990$ ) and Polynucleobacter (genus) was the third highest indicator (IndVal $=0.983$ ) of the zero salinity treatment. Unclassified Betaproteobacteria (class; IndVal $=0.936$ ) represented the salinity 5 environments, followed by Flavobacterium (genus; IndVal = 0.889 ) and Alcaligenaceae (family; IndVal $=0.852$ ). Bacteria representing Salinity 9 and 13 environments were less clear. In the more saline treatments, 5 of 8 OTUs were unclassified and were unresolved beyond the Bacterial domain (Supplementary Table S3). Planctomycetes had the third highest indicator value in the 9 psu treatments, and was only 1 of 4 classified OTUs indicative of that treatment (phylum; IndVal = 0.804). The presence of this phylum in 9 psu tanks represents a slight shift in community dominance from fresh to salt-tolerant taxa; however, the other top 3 indicator taxa of salinity 9 tanks were unclassified, so conclusions regarding key bacterial taxa involved remain elusive. Salinity 13 also had unclassified taxa identified in the top five indicators species; there were 2 classified and 2 unclassified taxa. The 2 classified taxa were Haliea (genus; IndVal $=0.869$ ) and Alphaproteobacteria (class; IndVal $=0.928$ ). Genus Haliea is a Gammaproteobacteria (class) with species isolated from aquatic marine environments.

\subsection{Ecosystem Function 0.6.1 Decomposition}

As bacterial richness increased the proportion of leaf mass remaining decreased, representing an increase in decomposition (estimate (log-odds scale) $=-0.0007$, standard error (log-odds scale) $=0.0002, z=$ $-3.04, p=0.002)$. As salinity increased, mass change decreased (estimate (log-odds scale) $=0.043$, standard error ( $\log$-odds scales) $=0.018, z=2.38, p=0.017)$. The salt-only mixing treatment had lower overall decomposition (less mass lost) than the mixed mixing treatment (estimate (log-odds scale) $=-0.19$, standard error(log-odds scale $)=0.086, z=-2.26, p=0.02$ ). Spartina alterniflora lost less material than Acer rubrum leaves (estimate:log link 1.1, standard error:log link 0.18, $z=5.9, p<<.001$ ) (Figure 6). In contrast, we were unable to detect an affect of zooplankton richness or any of the interaction terms with leaf type (all $p>0.05$ ). Overall the model accounted for a large fraction of the variation (pseudo $\left.R^{2}=0.66\right)$.

\subsubsection{Carbon mineralization}

In our first a priori model we found that carbon mineralization increased with observed bacterial richness (estimate: 0.003 , standard error: $0.001, t=2.78, p=0.008$ ) (Figure 7). Overall model fit was moderate (adjusted $R^{2}=0.31, F-$ statistic $=4.4$ on 5 and $32 \mathrm{DF}$ ). We were unable to detect an effect of zooplankton richness, mixing treatment, or salinity on carbon mineralization (all $p>0.5$ ).

However, in our exploratory model we found that carbon mineralization decreased in the mid-salinity treatments (Figure 8) (salinity ${ }^{2}$ : estimate: 8.2, standard error:1.4, $t=5.9, p<<0.001$ ) and that carbon mineralization increased with zooplankton richness (estimate: 0.5 , standard error:0.16, $t=3.1, p=0.003$ ). This model explained more variation than our a priori model (adjusted $R^{2}=0.4, F-$ statistic $=14.4$ on 5 and $84 \mathrm{DF}$ ). We were unable to detect an effect of microbial richness, mixing treatment, or the main affect of salinity on carbon mineralization (all $p>0.5$ ). Based on AIC, the second model with the squared salinity term, has more support (Delta AIC $=30)$.

\section{DISCUSSION}

Understanding how extreme environmental gradients and changing patterns of connectivity can influence community structure and ecosystem functions is becoming increasingly important as species assemblages shift to keep pace with climate change (Root et al., 2015). While the mixing of previously distinct communities from environmental change may have dire consequences for some species (Cahill et al., 2012), an increased capacity to maintain ecosystem functions in the face of those same environmental perturbations may also be expected due to introduction of redundant or tolerant species (e.g. Thompson and Shurin, 2012; de Boer et al., 2014; Mansour et al., 2018).

Our results for zooplankton diversity and observed microbial richness patterns are consistent with communities that are determined by strong abiotic filters (Figures 5, 4) (Leibold et al., 2017). Indeed, we found a clear delineation between freshwater and brackish water in our experiment (Figures 2,3) which suggests that abiotic filters are a strong and critical regulating force of the composition of zoo- and bacterio-planktonic communities at the fresh-brackish water interface. While we expected an increase in 
species richness in low to mid salinity pools due to sampling from a more diverse species pool (mixed salinity), the effect of species mixing in this study was likely masked by the strong effect of salinity on community composition (Mouquet and Loreau, 2003). Additionally, our experimental protocol permitted salinities and biotic communities to stabilize, which may have further buffered experimental pools against invasion (Supplementary Figure S7). Although a larger regional species pool (fresh and salt water species) might be expected to positively influence local diversity and function, fresh or salt water systems that have low levels of disturbance might be further resistant to invasion by new taxa (Symons and Arnott, 2013,2014 ) because of strong priority effects and competitive dominance hierarchies (e.g. Geange and Stier, 2009). Interestingly, we only observed changes in community structure in the 5 psu zooplankton community. Specifically, this community became more similar to a freshwater community in the mixedsalinity mixing treatment (Figure 2). In contrast, the 13 psu or 0 psu salinity communities did not change over time, suggesting that new species are unable to easily colonize and establish in these highly filtered and stable environments.

Different microbial taxa were representative of each of the four different salinity levels, supporting previous work that suggests salinity tolerance is a specialized trait that determines bacterial community composition (Martiny et al., 2015). In the freshwater treatment one of the key indicator taxa, the Proteobacteria phylum, is the most diverse phylum of bacteria both in terms of taxonomic and functional diversity. Within the phylum Proteobacteria, we found Rhodospirillales, which includes many species that contain photosynthetic pigments and function as photoheterotrophs. Alternatively, the main indicator in the 5 salinity treatment, Betaproteobacteria class, consists of aerobic or facultative bacteria, which are capable of living in dynamic (redox) environments. The taxa found in salinity 5 are not characterized as existing in any one specific salinity. This may be attributed to the bacteria in the salinity 5 tanks being able to persist through the salinity change from fresh to salinity 5 . For both 9 and 13 salinity we were unable to resolve the taxa of the most abundant OTUs. This suggests that less is known about these habitats in general and perhaps mid-salinity estuaries require more studies.

While it is not surprising that abiotic filtering had strong effects on community structure in our study, this study expands our understanding about how coastal systems may be affected by changes in salinity and species mixing. The observed changes in richness across salinity, in part, led to changes in ecosystem function. Indeed, in contrast to the responses of zooplankton, we found that bacterial richness increased with salinity, and that this increase in species richness was correlated with amount of decomposition. This result lends support to the hypothesis that changes in biodiversity can affect ecosystem function (Mouquet and Loreau, 2003). This effect is even more interesting because it acts inversely to the effect of salinity; as salinity increased, decomposition decreased overall (Figure 6). That bacterial richness increased with increased salinity and that decomposition amount increased with increased bacterial richness in our system suggests there is some small compensation by bacteria that is mitigating the effect of salinity. However, the effect may be temporary because the increase in richness over salinity is reduced over time (Figure 5). The smaller difference in richness across salinities from the beginning to the end of the experiment (Figure 5: Day 0 and 45) is driven by larger increases in richness in the freshwater treatments compared to the other treatments. However, because the freshwater communities did not become more similar to the salt communities over time (Figure 3), it is unlikely that the increase in observed bacterial richness is due to mixing of species pools via the mixed treatments. Instead it is likely that rare taxa, which we didn't detect at the beginning, become dominant in intermediate salinities (Rocca et al., 2019) and that there was higher immigration from natural sources to freshwater treatments than other treatments. We do, in fact, expect passive dispersal via wind (Nemergut et al., 2013). Another line of evidence supporting the idea that influxes from high saline environments can change ecosystem function is that the salt-only mixing treatments had lower decomposition than the other mixing scenarios. Based on the home-field advantage hypothesis we expected differential leaf litter decomposition based on the leaf litter's native habitat (e.g. Acer rubrum in freshwater); however, we found no detectable differences in decomposition among different leaf litter types as a function of salinity. There is very mixed evidence for the home-field advantage hypothesis generally though, so it comes as no surprise that we also were unable to find conclusive results. Instead, the relationship between habitat and decomposition may be better described along a continuum of decomposer-litter interactions (Freschet et al., 2012) or by C:N and C:P ratios of the litter (Kennedy and El-Sabaawi, 2017).

Bacterial communities are known to be important in linking terrestrial, fresh and marine carbon cycles through transport, mineralization, and storage of carbon (Ardón et al., 2016). Consistent with this expec- 
tation we found a positive correlation between bacterial communities and carbon mineralization in our $a$ priori model. While zooplankton communities have also been directly linked to carbon mineralization (Jonsson et al., 2001) and carbon cycling (Six and Maier-Reimer, 1996), they may only account for a small proportion of total mineralization (Jonsson et al., 2001). In our first model we did not find a direct link between zooplankton richness and carbon mineralization; this is likely a consequence of small sample sizes and small expected direct effect of zooplankton on total carbon mineralization. However, in our exploratory model, when we considered a quadratic term, we were able to detect a positive relationship with zooplankton richness and carbon mineralization. We also saw a decrease in carbon mineralization at mid-salinity compared to either extreme in our exploratory model. This result leaves room for more specific experiments to determine if this is repeatable and what mechanisms could cause a unimodal response. This highlights the need for future work on biodiversity-ecosystem functions to both clarify mechanism and better quantify the importance of exploring multiple trophic levels.

\section{CONCLUSIONS}

This study provides an important step toward understanding how mixing of communities along a salt gradient will affect local and regional patterns of diversity and ecosystem function. Future research should include perturbations such as variability in salinity within a single season, perhaps explicitly testing predictions made over changing heterogeneous landscapes as presented by Thompson and Gonzalez (2017). Additionally, our study further supports recent calls for experiments that explicitly use traits or taxonomic groups related to functions of interest to investigate links to ecosystem functions (e.g. Violle et al., 2007; Hébert et al., 2016a). Our results highlight the need to better understand how changes in the abiotic environment and mixing of novel communities interact to affect how ecosystems (such as coastal ponds) respond to the rapid environmental changes and accelerating rates of global change.

\section{FIGURES AND TABLES}

Table 1

\begin{tabular}{|l|llllllllll|}
\hline \multirow{2}{*}{ Source } & $\begin{array}{l}\text { 1st } \\
\text { Dispersal }\end{array}$ & SD & $\begin{array}{l}\text { 2nd } \\
\text { Dispersal }\end{array}$ & SD & $\begin{array}{l}\text { 3rd } \\
\text { Dispersal }\end{array}$ & SD & $\begin{array}{l}\text { 4th } \\
\text { Dispersal }\end{array}$ & SD & $\begin{array}{l}\text { 5th } \\
\text { Dispersal }\end{array}$ & SD \\
\hline 13 & 1.2 & 1.7 & 2.35 & 2.5 & 1.8 & 3.3 & 1.1 & 1.5 & 1.6 & 2.2 \\
0 & 3.4 & 7.1 & 7.24 & 9.9 & 4.1 & 6.1 & 11 & 18.8 & 4.6 & 6.9 \\
\hline
\end{tabular}


Figure 1
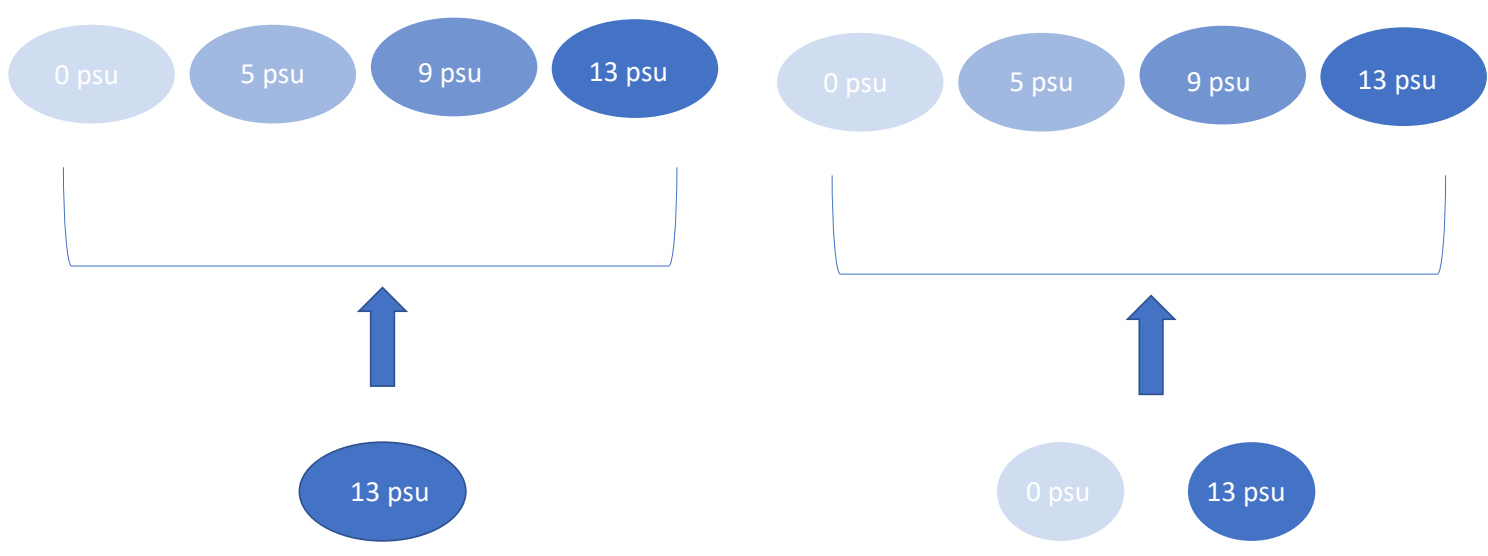
Figure 2

a. 0

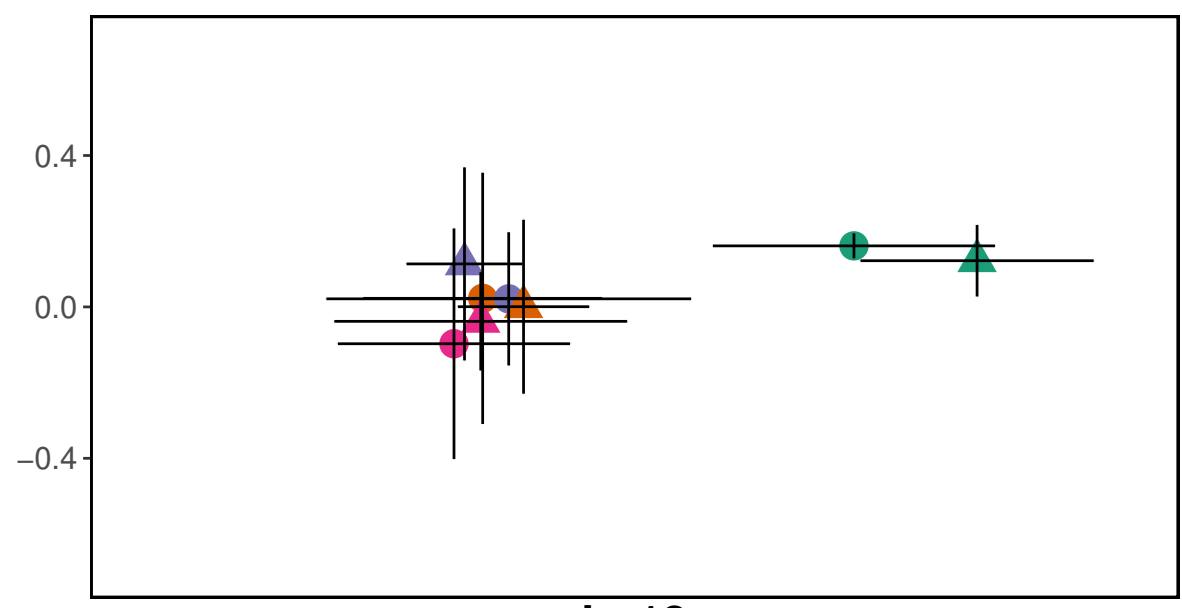

b. 18

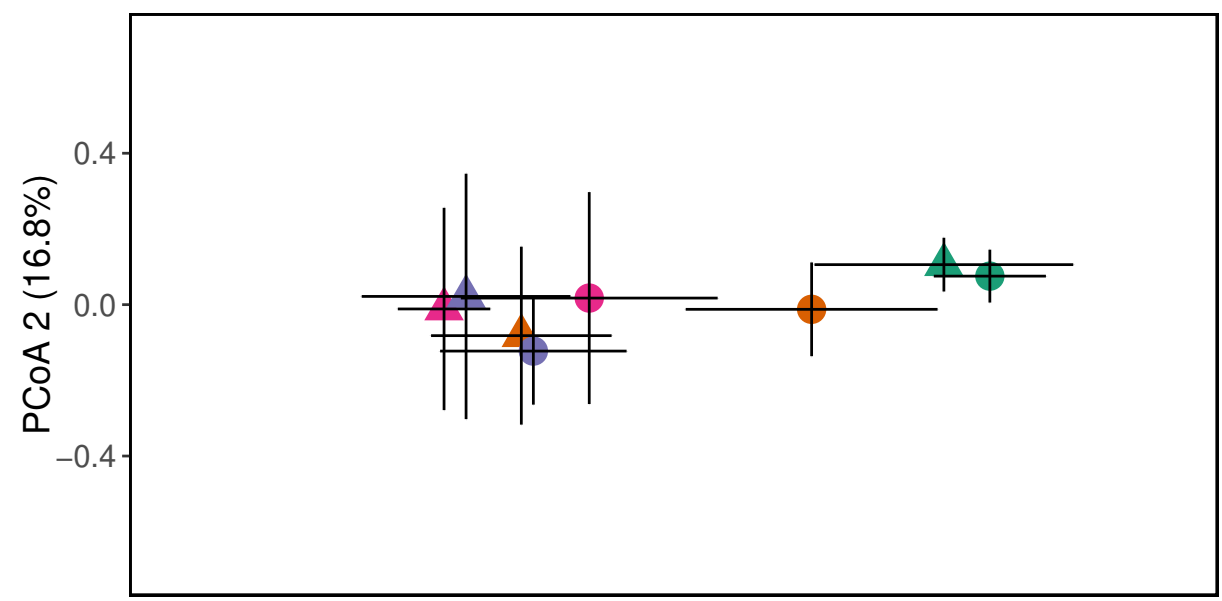

Mixing Treatment

Mixed Salt and Fresh

S Salt Only

Salinity

0

5

9

13

C. 45

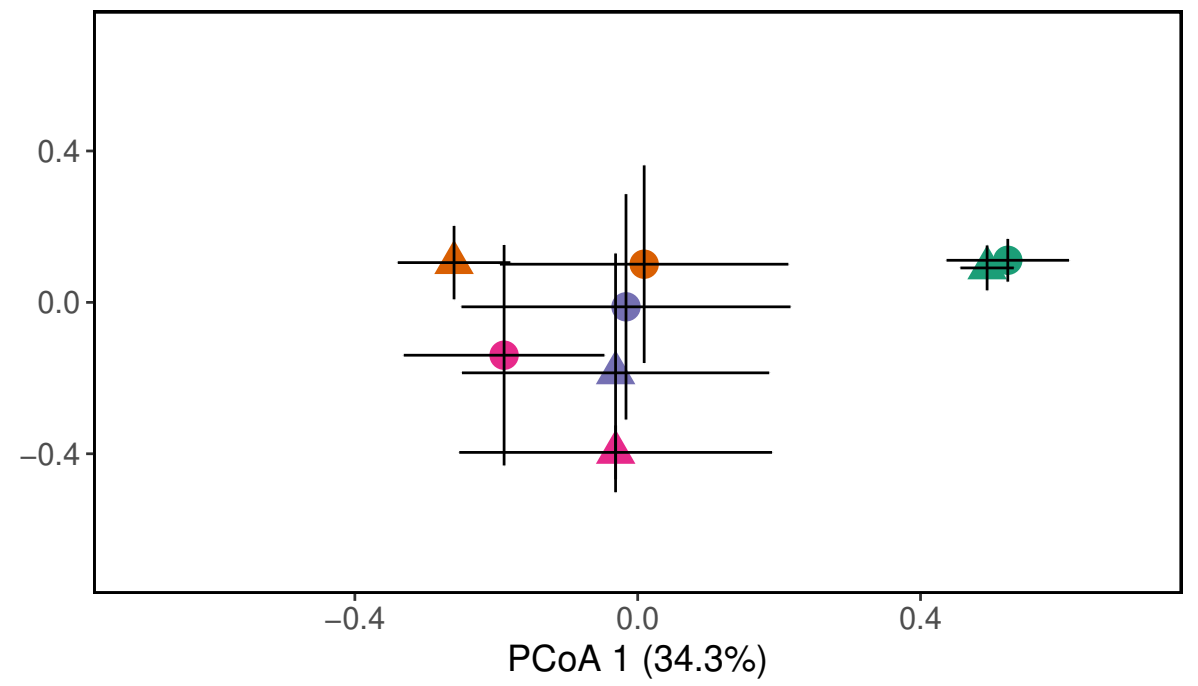


Figure 3

a. 0

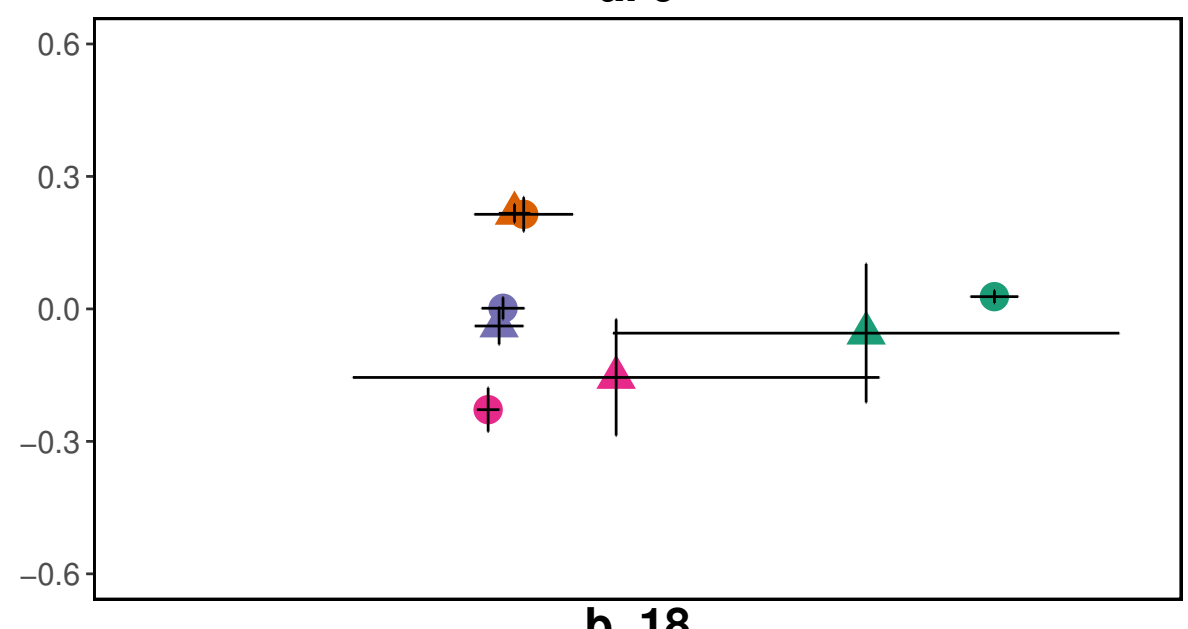

b. 18

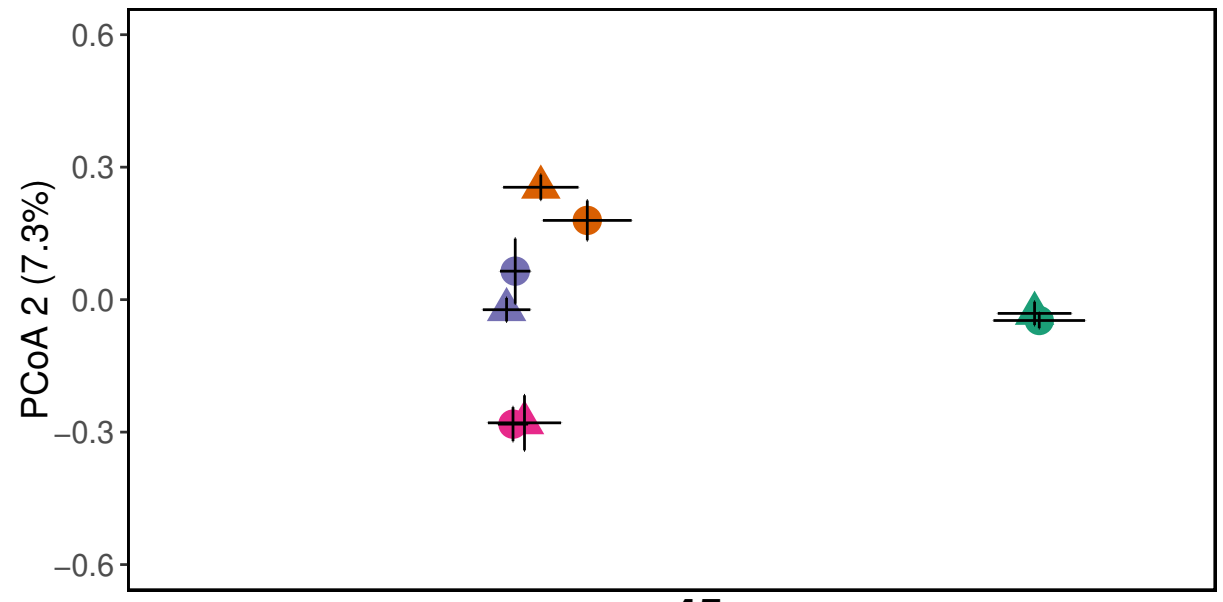

Mixing Treatment

Mixed Salt and Fresh

Salt Only

Salinity

0

5

9

13

C. 45

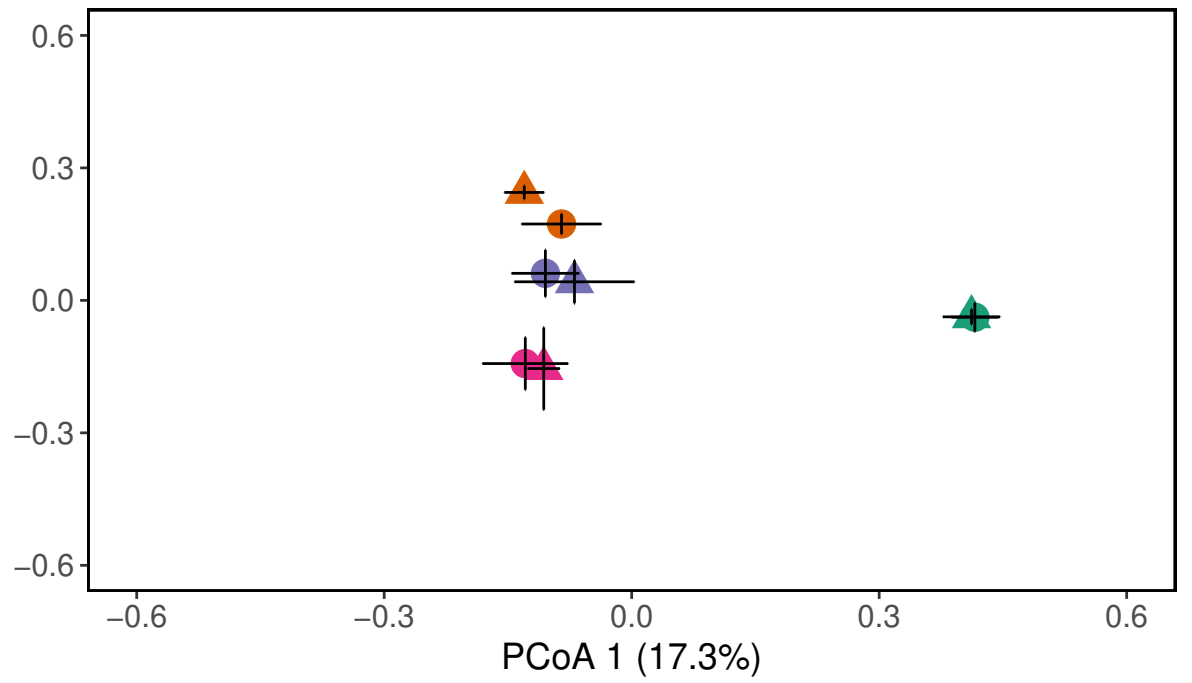


Figure 4

$\begin{array}{ll}\text { a. } 0 & \text { b. } 9\end{array}$

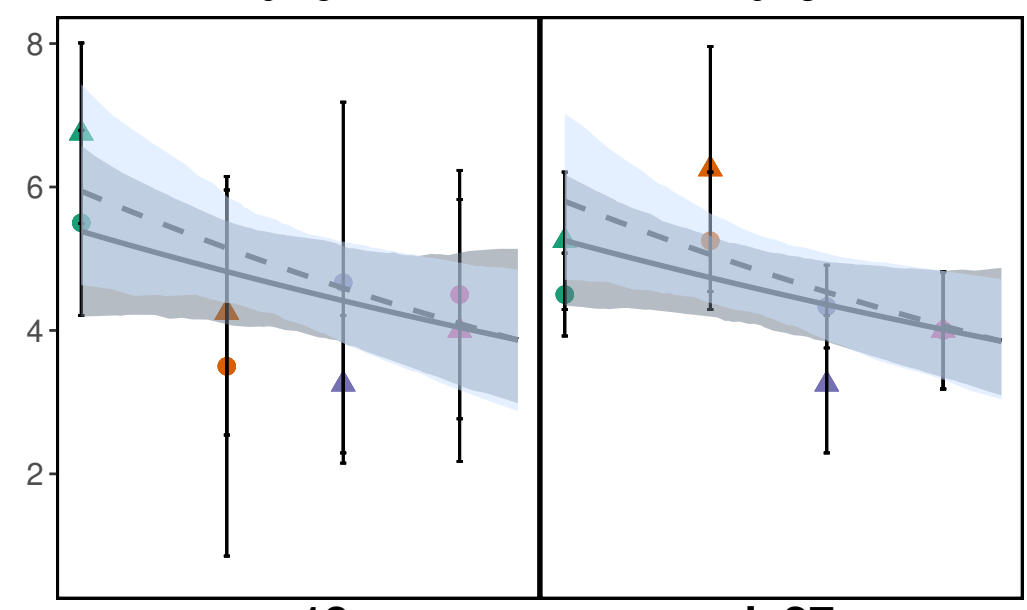

C. 18

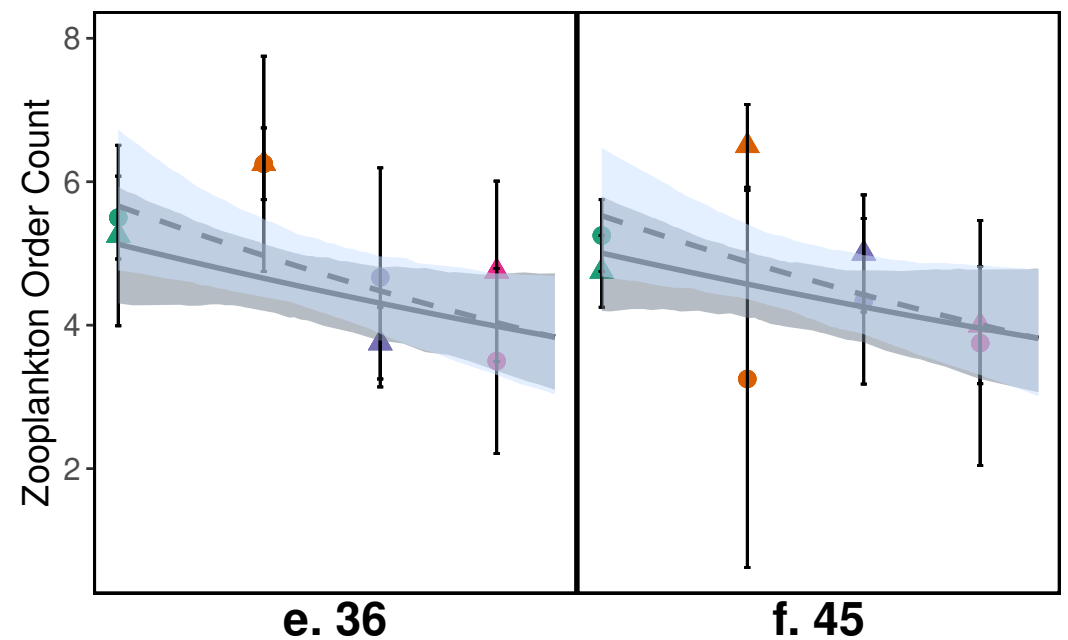

e. 36

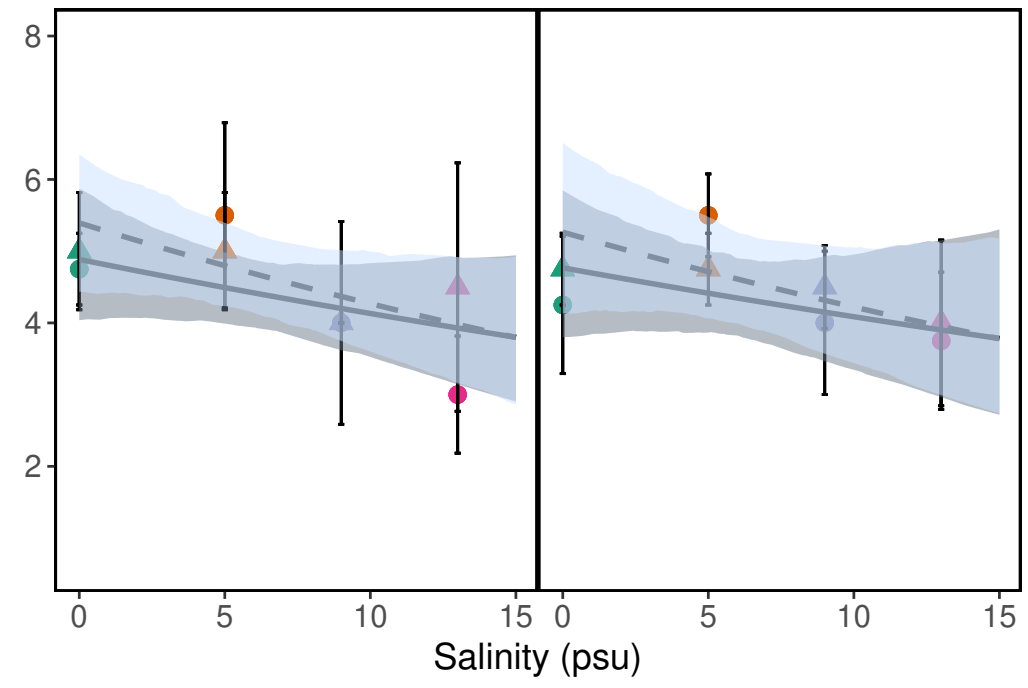

Mixing Treatment Prediction Lines

- Mixed Salt and Fresh

- Salt Only

Mixing Treatment

- Mixed Salt and Fresh

- Salt Only

Salinity Treatment

0

- 5

- 9

- 13 
Figure 5

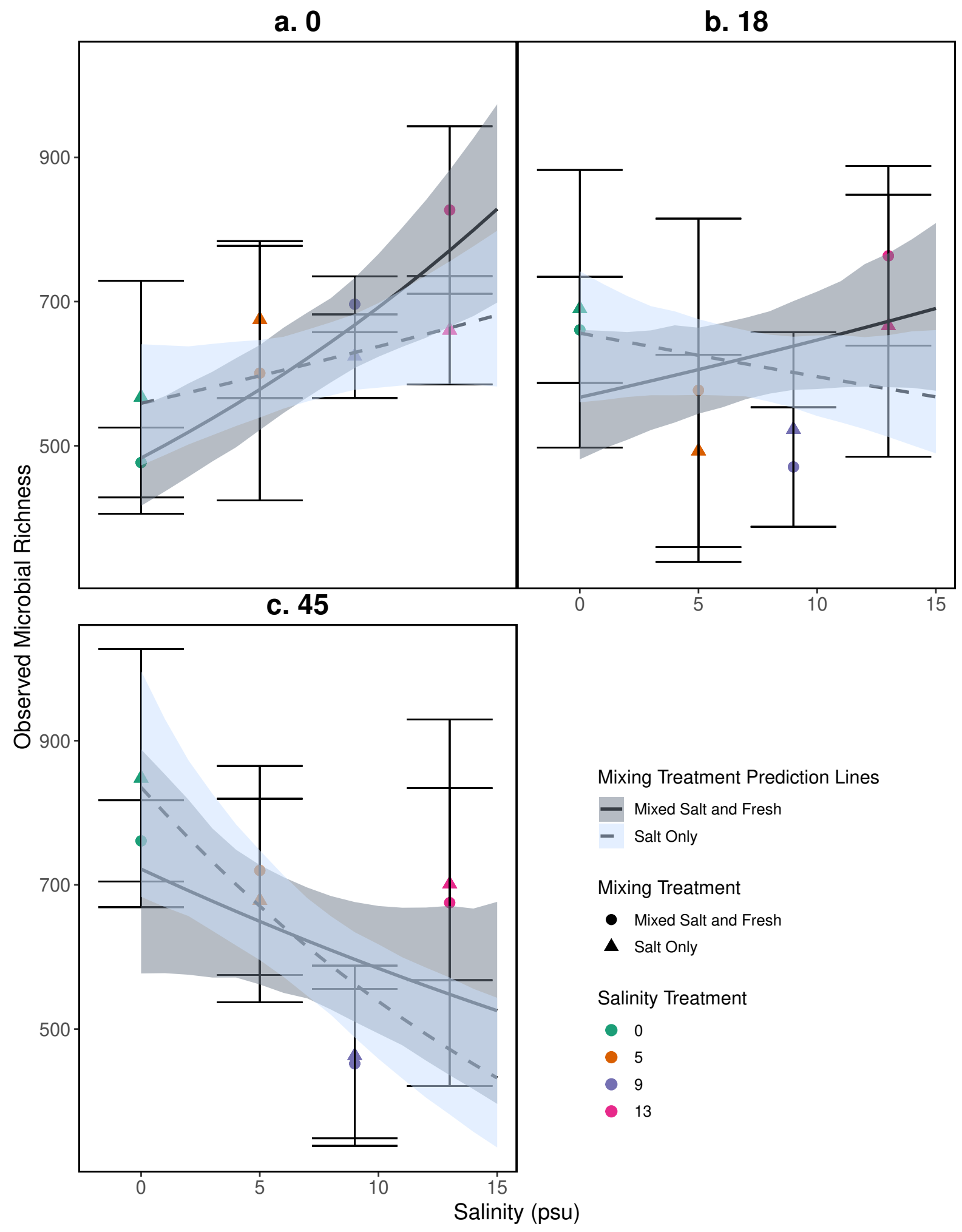


Figure 6

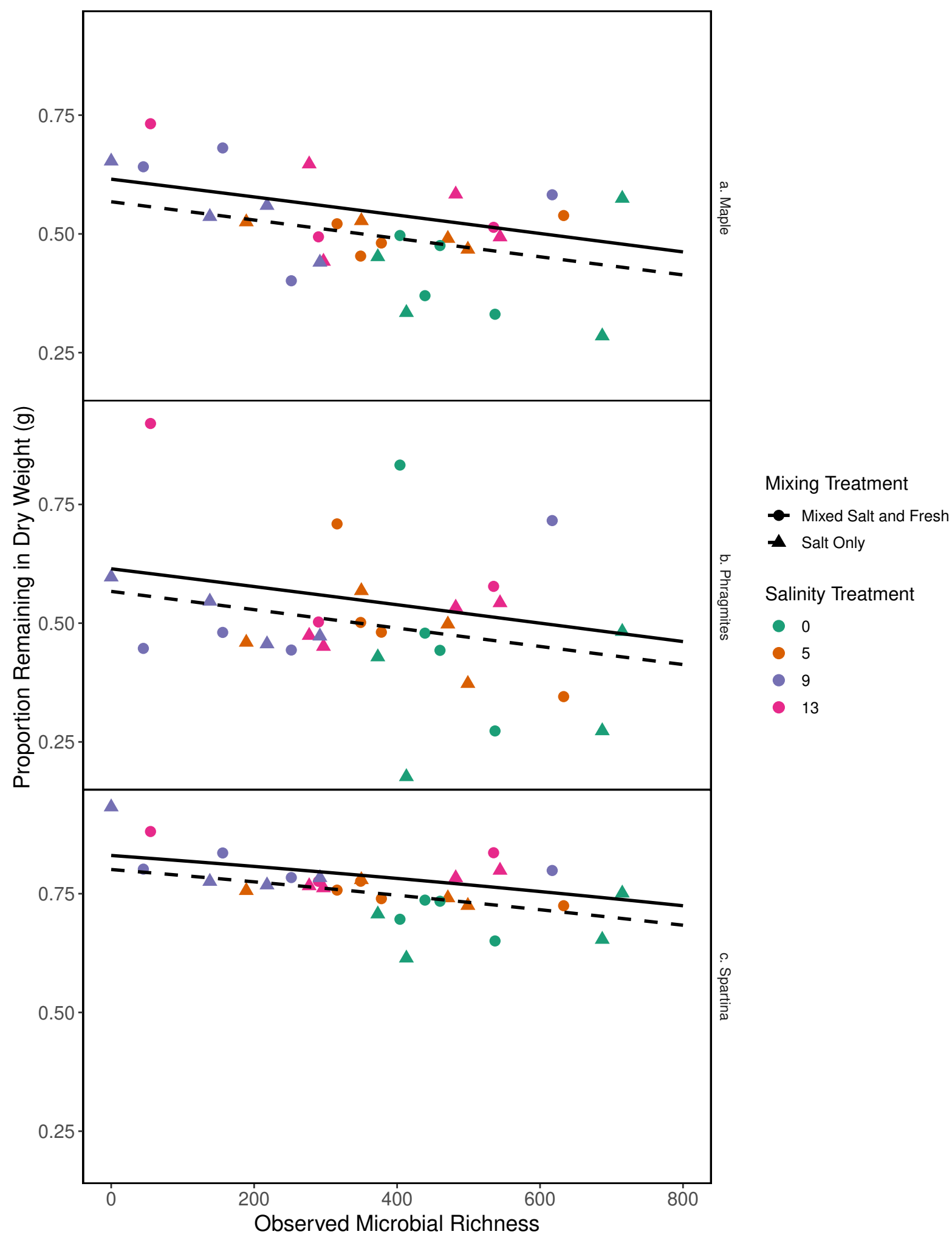


Figure 7

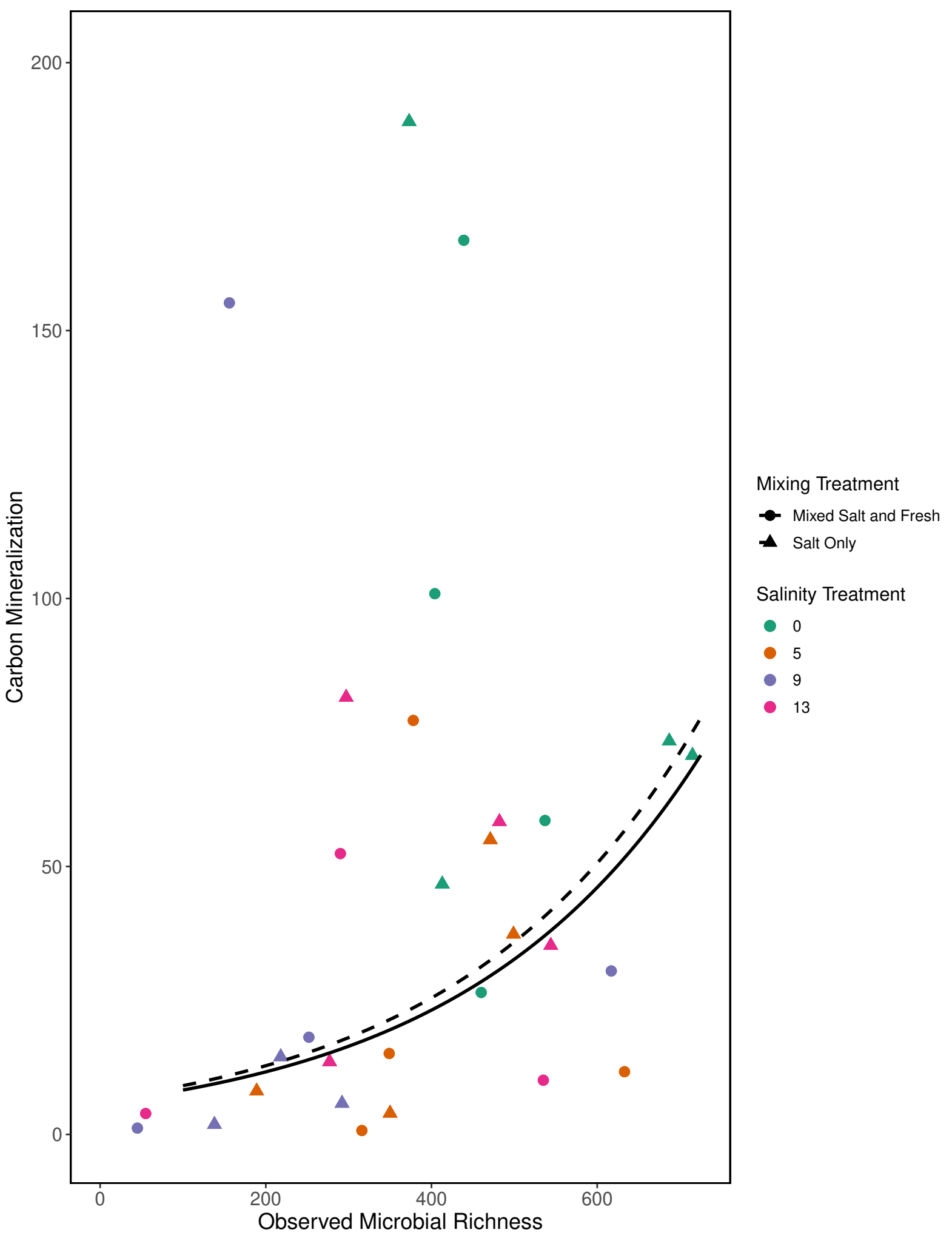


Figure 8

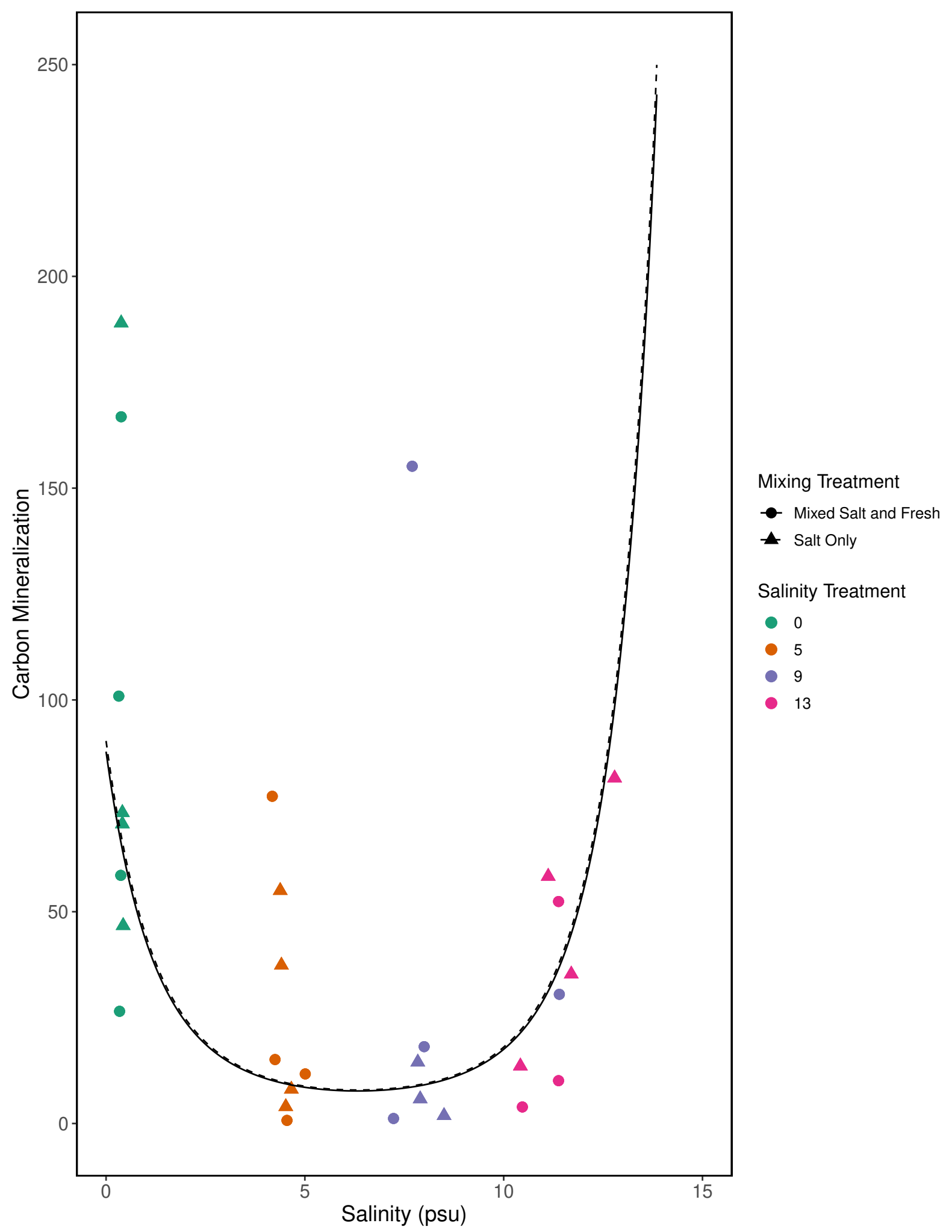




\section{TABLE AND FIGURE LEGENDS}

Table 1: Zooplankton abundance (mean \pm standard deviation) per liter for each dispersal source tank (13 psu or 0 psu). No mixing treatment was exclusively freshwater, instead a combination of half freshwater and half 13 psu.

Figure 1: Experimental design showing the four salinity treatments and the two dispersal treatments. Arrows indicate mixing treatment. This experimental design was replicated 4 times, except for 5 psu with mixed dispersal which was replicated 3 times.

Figure 2: PCoA for the relationship between zooplankton communities and salinity at three time points. Zooplankton communities are represented by their centroid. Error bars show standard deviation. Panels represent different sampling days: a) day 1 (starting community structure), b) day 18, and c) the final day (day 45). Shapes indicate dispersal treatment: circles show mixed salt and freshwater, triangles show salt water only mixing. Colors represent salinity treatment. Axes are PCoA 1 (x-axis) and PCoA 2 (y-axis).

Figure 3: PCoA for the relationship between microbial communities and salinity at three time points. Points represent the centroid of the bacterial community structure. Error bars represent standard deviation. Panels show different sampling days: a) day 1 (starting community structure), b) day 18, and c) the final day (day 45). All shapes and colors follow Figure 2.

Figure 4: Relationship between zooplankton order count and salinity. Each panel represents zooplankton richness (mean \pm standard deviation) at a single sampling day. Color indicates the salinity treatment. Shape indicates mixing treatment: circles show salt and fresh water community mixing and triangles show salt-only mixing. Lines are model estimates: solid lines represent predictions for the mixed fresh and salt water treatment and dotted lines show predictions for the salt-only mixing treatment. Predicted lines are transformed back to original scale. Envelopes show bootstrap 95\% confidence intervals.

Figure 5: Relationship between observed microbial richness and salinity. Panels represent different sampling days: a) day 1 (starting community structure), b) day 18, and c) the final day (day 45). Data and model estimates are shown on the original count scale. All symbols and colors match those in Figure 4.

Figure 6: Proportion of leaf litter remaining in relation to microbial richness. The y-axis shows the proportion of leaf litter remaining at the end of the experiment; the more leaf litter remaining the less decomposition occurred. Panels represent change in weight in each leaf litter type: a) Acer rubrum, b) Phragmites australis, and c) Spartina alternaflora. Points are colored by salinity treatment and shaped by leaf litter type. Lines represent model predictions: solid lines represent predictions for the mixed fresh and salt water treatment and dotted lines show predictions for the salt-only mixing treatment. The estimates shown here were obtained using average zooplankton richness (4.5) and mean salinity (6).

Figure 7: Carbon mineralization given observed microbial richness. Points are colored by salinity treatment. Lines represent model predictions: solid lines represent predictions for the mixed fresh and salt water treatment and dotted lines show predictions for the salt-only mixing treatment. The estimates shown here were obtained using average zooplankton richness (4.5) and mean salinity (6).

Figure 8: Exploratory analysis of the relationship between carbon mineralization and salinity. Points are colored by salinity treatments and shapes by mixing treatment. The estimates shown here were obtained using average zooplankton richness (4.5) and mean observed bacterial richness (380.4).

\section{ACKNOWLEDGMENTS}

We would like to thank Spencer Wilkinson, Amanda Dunn, and Mary-Grace Lee for help with data collection. We would like to thank the Coastal Studies Institute (CSI) for use of their space and Mike Piehler and Corey Adams for logistical help at CSI. 


\section{REFERENCES}

Al-Busaidi, K. T., Buerkert, A., and Joergensen, R. G. (2014). Carbon and nitrogen mineralization at different salinity levels in omani low organic matter soils. Journal of Arid Environments, 100:106-110.

Albecker, M. A. and McCoy, M. W. (2017). Adaptive responses to salinity stress across multiple life stages in anuran amphibians. Frontiers in zoology, 14(1):40.

Albecker, M. A. and McCoy, M. W. (2019). Local adaptation for enhanced salt tolerance reduces non-adaptive plasticity caused by osmotic stress. Evolution.

Apprill, A., McNally, S., Parsons, R., and Weber, L. (2015). Minor revision to v4 region ssu rrna 806r gene primer greatly increases detection of sar11 bacterioplankton. Aquatic Microbial Ecology, 75(2):129-137.

Ardón, M., Helton, A. M., and Bernhardt, E. S. (2016). Drought and saltwater incursion synergistically reduce dissolved organic carbon export from coastal freshwater wetlands. Biogeochemistry, 127(23):411-426.

Barnett, A. J., Finlay, K., and Beisner, B. E. (2007). Functional diversity of crustacean zooplankton communities: towards a trait-based classification. Freshwater Biology, 52(5):796-813.

Bate, G. C., Whitfield, A. K., Adams, J. B., Huizinga, P., and Wooldridge, T. H. (2002). The importance of the river-estuary interface (REI) zone in estuaries. Water SA, 28(3):271-280.

Bates, D., Mächler, M., Bolker, B., and Walker, S. (2015). Fitting linear mixed-effects models using lme4. Journal of Statistical Software, 67(1):1-48.

Bolker, B. M. (2008). Ecological models and data in R. Princeton University Press.

Breckenridge, J., Bollens, S., Rollwagen-Bollens, G., and Roegner, G. C. (2015). Plankton assemblage variability in a river-dominated temperate estuary during late spring (high-flow) and late summer (low-flow) periods. Estuaries and coasts, 38(1):93-103.

Bridgham, S. D., Megonigal, J. P., Keller, J. K., Bliss, N. B., and Trettin, C. (2006). The carbon balance of north american wetlands. Wetlands, 26(4):889-916.

Cahill, A. E., Aiello-Lammens, M. E., Fisher-Reid, M. C., Hua, X., Karanewsky, C. J., Ryu, H. Y., Sbeglia, G. C., Spagnolo, F., Waldron, J. B., Warsi, O., and Wiens, J. J. (2012). How does climate change cause extinction? Proc. R. Soc. B, page rspb20121890.

Caporaso, J. G., Lauber, C. L., Walters, W. A., Berg-Lyons, D., Huntley, J., Fierer, N., Owens, S. M., Betley, J., Fraser, L., Bauer, M., Gormley, N., Gilbert, J. A., Smith, G., and Knight, R. (2012). Ultrahigh-throughput microbial community analysis on the illumina hiseq and miseq platforms. The ISME journal, 6(8):1621.

Caporaso, J. G., Lauber, C. L., Walters, W. A., Berg-Lyons, D., Lozupone, C. A., Turnbaugh, P. J., Fierer, N., and Knight, R. (2011). Global patterns of 16s rrna diversity at a depth of millions of sequences per sample. Proceedings of the National Academy of Sciences, 108(Supplement 1):4516-4522.

Chambers, L. G., Reddy, K. R., and Osborne, T. Z. (2011). Short-term response of carbon cycling to salinity pulses in a freshwater wetland. Soil Science Society of America Journal, 75(5):2000-2007.

Coci, M., Riechmann, D., Bodelier, P. L., Stefani, S., Zwart, G., and Laanbroek, H. J. (2005). Effect of salinity on temporal and spatial dynamics of ammonia-oxidising bacteria from intertidal freshwater sediment. FEMS microbiology ecology, 53(3):359-368.

Connolly, C. T., Sobczak, W. V., and Findlay, S. E. (2014). Salinity effects on phragmites decomposition dynamics among the hudson river's freshwater tidal wetlands. Wetlands, 34(3):575-582.

Craft, C., Clough, J., Ehman, J., Jove, S., Park, R., Pennings, S., Guo, H., and Machmuller, M. (2009). Forecasting the effects of accelerated sea-level rise on tidal marsh ecosystem services. Frontiers in Ecology and the Environment, 7(2):73-78.

de Boer, M. K., Moor, H., Matthiessen, B., Hillebrand, H., and Eriksson, B. K. (2014). Dispersal restricts local biomass but promotes the recovery of metacommunities after temperature stress. Oikos, 123(6):762-768.

de Groot, R. S., Wilson, M. a., and Boumans, R. M. (2002). A typology for the classification, description and valuation of ecosystem functions, goods and services. Ecological Economics, 41(3):393-408.

Dodson, S. I. (1992). Predicting crustacean zooplankton species richness. Limnology and Oceanography, 37(4):848-856.

Dufrêne, M. and Legendre, P. (1997). Species assemblages and indicator species: the need for a flexible asymmetrical approach. Ecological monographs, 67(3):345-366.

Dupont, C. L., Larsson, J., Yooseph, S., Ininbergs, K., Goll, J., Asplund-Samuelsson, J., McCrow, J. P., 
Celepli, N., Allen, L. Z., Ekman, M., Lucas, A. J., Hagström, , Thiagarajan, M., Brindefalk, B., Richter, A. R., Andersson, A. F., Tenney, A., Lundin, D., Tovchigrechko, A., Nylander, J. A. A., Brami, D., Badger, J. H., Allen, A. E., Rusch, D. B., Hoffman, J., Norrby, E., Friedman, R., Pinhassi, J. J., Venter, C., and Bergman, B. (2014). Functional tradeoffs underpin salinity-driven divergence in microbial community composition. PloS one, 9(2):e89549.

Eiler, A., Zaremba-Niedzwiedzka, K., Martínez-García, M., McMahon, K. D., Stepanauskas, R., Andersson, S. G., and Bertilsson, S. (2014). Productivity and salinity structuring of the microplankton revealed by comparative freshwater metagenomics. Environmental microbiology, 16(9):2682-2698.

Franzitta, G., Hanley, M. E., Airoldi, L., Baggini, C., Bilton, D. T., Rundle, S. D., and Thompson, R. C. (2015). Home advantage? decomposition across the freshwater-estuarine transition zone varies with litter origin and local salinity. Marine environmental research, 110:1-7.

Freschet, G. T., Aerts, R., and Cornelissen, J. H. (2012). Multiple mechanisms for trait effects on litter decomposition: moving beyond home-field advantage with a new hypothesis. Journal of Ecology, 100(3):619-630.

Geange, S. W. and Stier, A. C. (2009). Order of arrival affects competition in two reef fishes. Ecology, 90(10):2868-2878.

Gholz, H. L., Wedin, D. A., Smitherman, S. M., Harmon, M. E., and Parton, W. J. (2000). Longterm dynamics of pine and hardwood litter in contrasting environments: toward a global model of decomposition. Global Change Biology, 6(7):751-765.

Grün, B., Kosmidis, I., and Zeileis, A. (2012). Extended beta regression in R: Shaken, stirred, mixed, and partitioned. Journal of Statistical Software, 48(11):1-25.

Hall, C. J. and Burns, C. W. (2002). Environmental gradients and zooplankton distribution in a shallow, tidal lake. Archiv für Hydrobiologie, pages 485-497.

Hébert, M.-P., Beisner, B. E., and Maranger, R. (2016a). Linking zooplankton communities to ecosystem functioning: toward an effect-trait framework. Journal of Plankton Research, 39(1):3-12.

Hébert, M.-P., Beisner, B. E., and Maranger, R. (2016b). A meta-analysis of zooplankton functional traits influencing ecosystem function. Ecology, 97(4):1069-1080.

Helenius, L. K., Leskinen, E., Lehtonen, H., and Nurminen, L. (2017). Spatial patterns of littoral zooplankton assemblages along a salinity gradient in a brackish sea: a functional diversity perspective. Estuarine, Coastal and Shelf Science, 198:400-412.

Herbert, E. R., Boon, P., Burgin, A. J., Neubauer, S. C., Franklin, R. B., Ardón, M., Hopfensperger, K. N., Lamers, L. P., and Gell, P. (2015). A global perspective on wetland salinization: ecological consequences of a growing threat to freshwater wetlands. Ecosphere, 6(10):1-43.

Hintz, W. D. and Relyea, R. A. (2017). Impacts of road deicing salts on the early-life growth and development of a stream salmonid: salt type matters. Environmental pollution, 223:409-415.

Hopkinson, C. S., Cai, W.-J., and Hu, X. (2012). Carbon sequestration in wetland dominated coastal systems-a global sink of rapidly diminishing magnitude. Current Opinion in Environmental Sustainability, 4(2):186-194.

Hunt, H., Ingham, E., Coleman, D., Elliott, E., and Reid, C. (1988). Nitrogen limitation of production and decomposition in prairie, mountain meadow, and pine forest. Ecology, 69(4):1009-1016.

Isla, A., Scharek, R., and Latasa, M. (2015). Zooplankton diel vertical migration and contribution to deep active carbon flux in the nw mediterranean. Journal of Marine Systems, 143:86-97.

Johnson, W. S. and Allen, D. M. (2012). Zooplankton of the Atlantic and Gulf coasts: a guide to their identification and ecology. JHU Press.

Jones, S. E. and McMahon, K. D. (2009). Species-sorting may explain an apparent minimal effect of immigration on freshwater bacterial community dynamics. Environmental microbiology, 11(4):905913.

Jonsson, A., Meili, M., Bergström, A.-K., and Jansson, M. (2001). Whole-lake mineralization of allochthonous and autochthonous organic carbon in a large humic lake (örträsket, n. sweden). Limnology and oceanography, 46(7):1691-1700.

Kemp, A. C., Horton, B. P., Culver, S. J., Corbett, D. R., van de Plassche, O., Gehrels, W. R., Douglas, B. C., and Parnell, A. C. (2009). Timing and magnitude of recent accelerated sea-level rise (north carolina, united states). Geology, 37(11):1035-1038.

Kennedy, K. and El-Sabaawi, R. W. (2017). A global meta-analysis of exotic versus native leaf decay in stream ecosystems. Freshwater biology, 62(6):977-989. 
Kimmel, D. (2011). Plankton consumer groups: Copepods.

Kirwan, M. L. and Megonigal, J. P. (2013). Tidal wetland stability in the face of human impacts and sea-level rise. Nature, 504(7478):53-60.

Kopp, R. E., Horton, B. P., Kemp, A. C., and Tebaldi, C. (2015). Past and future sea-level rise along the coast of north carolina, usa. Climatic Change, 132(4):693-707.

Kozich, J. J., Westcott, S. L., Baxter, N. T., Highlander, S. K., and Schloss, P. D. (2013). Development of a dual-index sequencing strategy and curation pipeline for analyzing amplicon sequence data on the miseq illumina sequencing platform. Applied and environmental microbiology, 79(17):5112-5120.

Langenheder, S., Kisand, V., Wikner, J., and Tranvik, L. J. (2003). Salinity as a structuring factor for the composition and performance of bacterioplankton degrading riverine doc. FEMS Microbiology Ecology, 45(2): 189-202.

Leibold, M. A., Chase, J. M., and Ernest, S. M. (2017). Community assembly and the functioning of ecosystems: how metacommunity processes alter ecosystems attributes. Ecology, 98(4):909-919.

Lettice, S., Jansen, M. A., and Chapman, D. V. (2011). Differential decomposition patterns of marine and terrestrial biomass in a coastal lagoon. GeoEcoMarina, 17.

Logares, R., Bråte, J., Bertilsson, S., Clasen, J. L., Shalchian-Tabrizi, K., and Rengefors, K. (2009). Infrequent marine-freshwater transitions in the microbial world. Trends in microbiology, 17(9):414422.

Lopes, M. L., Martins, P., Ricardo, F., Rodrigues, A. M., and Quintino, V. (2011). In situ experimental decomposition studies in estuaries: A comparison of phragmites australis and fucus vesiculosus. Estuarine, Coastal and Shelf Science, 92(4):573-580.

Makarewicz, J. C. and Likens, G. E. (1979). Structure and function of the zooplankton community of mirror lake, new hampshire. Ecological Monographs, 49(1):109-127.

Mansour, I., Heppell, C. M., Ryo, M., and Rillig, M. C. (2018). Application of the microbial community coalescence concept to riverine networks. Biological Reviews, 93(4):1832-1845.

Martiny, J. B., Jones, S. E., Lennon, J. T., and Martiny, A. C. (2015). Microbiomes in light of traits: a phylogenetic perspective. Science, 350(6261):aac9323.

Mcleod, E., Chmura, G. L., Bouillon, S., Salm, R., Björk, M., Duarte, C. M., Lovelock, C. E., Schlesinger, W. H., and Silliman, B. R. (2011). A blueprint for blue carbon: toward an improved understanding of the role of vegetated coastal habitats in sequestering co2. Frontiers in Ecology and the Environment, 9(10):552-560.

Mitsch, W. J., Bernal, B., Nahlik, A. M., Mander, Ü., Zhang, L., Anderson, C. J., Jørgensen, S. E., and Brix, H. (2013). Wetlands, carbon, and climate change. Landscape Ecology, 28(4):583-597.

Mouquet, N. and Loreau, M. (2003). Community Patterns in Source-Sink Metacommunities. The American Naturalist, 162(5):544-557.

Nemergut, D. R., Schmidt, S. K., Fukami, T., O’Neill, S. P., Bilinski, T. M., Stanish, L. F., Knelman, J. E., Darcy, J. L., Lynch, R. C., Wickey, P., and Ferrenberg, S. (2013). Patterns and processes of microbial community assembly. Microbiol. Mol. Biol. Rev., 77(3):342-356.

Nicholls, R. J. and Cazenave, A. (2010). Sea Level Rise and Its Impact on Coastal Zones. Science, 328(2010):1517-1520.

Nielsen, D. L., Brock, M. A., Vogel, M., and Petrie, R. (2008). From fresh to saline: a comparison of zooplankton and plant communities developing under a gradient of salinity with communities developing under constant salinity levels. Marine and Freshwater Research, 59(7):549-559.

Oksanen, J., Blanchet, F. G., Friendly, M., Kindt, R., Legendre, P., McGlinn, D., Minchin, P. R., O'Hara, R. B., Simpson, G. L., Solymos, P., Stevens, M. H. H., Szoecs, E., and Wagner, H. (2016). vegan: Community Ecology Package. R package version 2.4-1.

Parada, A. E., Needham, D. M., and Fuhrman, J. A. (2016). Every base matters: assessing small subunit rrna primers for marine microbiomes with mock communities, time series and global field samples. Environmental microbiology, 18(5):1403-1414.

Pennak, R. W. (1953). Fresh-water invertebrates of the united states. In Fresh-water invertebrates of the United States. Ronald Press.

Poffenbarger, H. J., Needelman, B. A., and Megonigal, J. P. (2011). Salinity influence on methane emissions from tidal marshes. Wetlands, 31(5):831-842.

Quast, C., Pruesse, E., Yilmaz, P., Gerken, J., Schweer, T., Yarza, P., Peplies, J., and Glöckner, F. O. (2012). The silva ribosomal rna gene database project: improved data processing and web-based tools. 
Nucleic acids research, 41(D1):D590-D596.

Quintino, V., Sangiorgio, F., Ricardo, F., Mamede, R., Pires, A., Freitas, R., Rodrigues, A. M., and Basset, A. (2009). In situ experimental study of reed leaf decomposition along a full salinity gradient. Estuarine, Coastal and Shelf Science, 85(3):497-506.

R Core Team (2016). R: a Language and Environment for Statistical Computing. R Foundation for Statistical Computing, Vienna, Austria.

Reice, S. R. and Herbst, G. (1982). The role of salinity in decomposition of leaves of phragmites australis in desert streams. Journal of Arid Environments, 5(4):361-368.

Roberts, D. W. (2016). labdsv: Ordination and Multivariate Analysis for Ecology. R package version 1.8-0.

Rocca, J. D., Simonin, M., Wright, J., Washburne, A., and Bernhardt, E. S. (2019). Rare microbial taxa emerge when communities collide: Freshwater and marine microbiome responses to experimental seawater intrusion. bioRxiv, page 550756.

Rognes, T., Flouri, T., Nichols, B., Quince, C., and Mahé, F. (2016). Vsearch: a versatile open source tool for metagenomics. PeerJ, 4:e2584.

Root, T. L., Hall, K. R., Herzog, M. P., and Howell, C. A. (2015). Biodiversity in a changing climate: linking science and management in conservation. Univ of California Press.

Schäfer, R. B., Bundschuh, M., Rouch, D. A., Szöcs, E., Peter, C., Pettigrove, V., Schulz, R., Nugegoda, D., and Kefford, B. J. (2012). Effects of pesticide toxicity, salinity and other environmental variables on selected ecosystem functions in streams and the relevance for ecosystem services. Science of the Total Environment, 415:69-78.

Schallenberg, M., Hall, C. J., and Burns, C. W. (2003). Consequences of climate-induced salinity increases on zooplankton abundance and diversity in coastal lakes. Marine ecology progress series, 251:181-189.

Schimel, J. and Schaeffer, S. M. (2012). Microbial control over carbon cycling in soil. Frontiers in microbiology, 3:348.

Schloss, P. D., Westcott, S. L., Ryabin, T., Hall, J. R., Hartmann, M., Hollister, E. B., Lesniewski, R. A., Oakley, B. B., Parks, D. H., Robinson, C. J., Sahl, J. W., Stres, B., Thallinger, G. G., Van Horn, D. J., and Weber, C. F. (2009). Introducing mothur: open-source, platform-independent, communitysupported software for describing and comparing microbial communities. Applied and environmental microbiology, 75(23):7537-7541.

Setia, R., Marschner, P., Baldock, J., Chittleborough, D., Smith, P., and Smith, J. (2011). Salinity effects on carbon mineralization in soils of varying texture. Soil biology and biochemistry, 43(9):1908-1916.

Six, K. D. and Maier-Reimer, E. (1996). Effects of plankton dynamics on seasonal carbon fluxes in an ocean general circulation model. Global Biogeochemical Cycles, 10(4):559-583.

Snucins, E. and John, G. (2000). Interannual variation in the thermal structure of clear and colored lakes. Limnology and Oceanography, 45(7):1639-1646.

Staddon, P., Lindo, Z., Crittenden, P. D., Gilbert, F., and Gonzalez, A. (2010). Connectivity, non-random extinction and ecosystem function in experimental metacommunities. Ecology Letters, 13(5):543-552.

Stagg, C. L., Baustian, M. M., Perry, C. L., Carruthers, T. J., and Hall, C. T. (2018). Direct and indirect controls on organic matter decomposition in four coastal wetland communities along a landscape salinity gradient. journal of ecology, 106(2):655-670.

Symons, C. C. and Arnott, S. E. (2013). Regional zooplankton dispersal provides spatial insurance for ecosystem function. Global change biology, 19(5):1610-9.

Symons, C. C. and Arnott, S. E. (2014). Timing is everything: priority effects alter community invasibility after disturbance. Ecology and evolution, 4(4):397-407.

Thompson, P. L. and Gonzalez, A. (2017). Dispersal governs the reorganization of ecological networks under environmental change. Nature ecology \& evolution, 1(6):0162.

Thompson, P. L. and Shurin, J. B. (2012). Regional zooplankton biodiversity provides limited buffering of pond ecosystems against climate change. The Journal of animal ecology, 81(1):251-9.

Venables, W. N. and Ripley, B. D. (2013). Modern applied statistics with S-PLUS. Springer Science \& Business Media.

Violle, C., Navas, M.-L., Vile, D., Kazakou, E., Fortunel, C., Hummel, I., and Garnier, E. (2007). Let the concept of trait be functional! Oikos, 116(5):882-892.

Weston, N. B., Dixon, R. E., and Joye, S. B. (2006). Ramifications of increased salinity in tidal freshwater sediments: Geochemistry and microbial pathways of organic matter mineralization. Journal 
of Geophysical Research: Biogeosciences, 111(G1).

Wieski, K., Guo, H., Craft, C. B., and Pennings, S. C. (2010). Ecosystem functions of tidal fresh, brackish, and salt marshes on the georgia coast. Estuaries and Coasts, 33(1):161-169.

Zervoudaki, S., Nielsen, T. G., and Carstensen, J. (2009). Seasonal succession and composition of the zooplankton community along an eutrophication and salinity gradient exemplified by danish waters. Journal of plankton research, 31(12):1475-1492. 